09

\title{
Корреляция между параметрами дисперсионных зависимостей показателей преломления и координационными числами катионов для кристаллов семейства лангасита
}

\author{
(C) Н.И. Сорокин
}

Институт кристаллографии им. А.В. Шубникова ФНИЦ „Кристаллография и фотоника“ РАН, Москва, Россия

E-mail: nsorokin1@yandex.ru

Поступила в Редакцию 6 июля 2020 г.

В окончательной редакции 6 июля 2020 г.

Принята к публикации 8 июля 2020 г.

Для оптических кристаллов семейства лангасита $\mathrm{La}_{3} \mathrm{Ga}_{5} \mathrm{SiO}_{14}$ (структурный тип $\mathrm{Ca}_{3} \mathrm{Ga}_{2} \mathrm{Ge}_{4} \mathrm{O}_{14}$, пр. гр. P321) обнаружена корреляция между параметрами дисперсионных кривых показателей преломления и координационными числами катионов в их структурах.

Ключевые слова: лангасит, оксиды, монокристаллы, показатель преломления, координационное число.

DOI: $10.21883 /$ FTT.2020.11.50068.142

\section{1. Введение}

Сложные оксиды семейства лангасита $\left(\mathrm{La}_{3} \mathrm{Ga}_{5} \mathrm{SiO}_{14}\right)$ относятся к структурному типу $\mathrm{Ca}_{3} \mathrm{Ga}_{2} \mathrm{Ge}_{4} \mathrm{O}_{14}$ (пр.гр. Р321). Их химическую формулу можно записать в виде $A_{3} B C_{3} D_{2} \mathrm{O}_{14}$, где катионы $A, B, C$ и $D$ расположены в четырех типах позиций - правильных системах точек пр.гр. P321. Способность структуры лангасита к широким изоморфным замещениям катионов приводит к усложнению химического состава и получению большого числа новых кристаллов.

Кристаллы семейства лангасита являются многофункциональными материалами, обладающими пьезоэлектрическими, оптическими, лазерными, люминесцентными, акустическими и магнитными свойствами. Их активные исследования включены в динамично развивающиеся направления в пьезотехнике, акустоэлектронике, фотонике и физике мультиферроиков (см. ссылки в [1]). Работы в области получения новых лангаситовых кристаллов и исследования их атомного строения и физических свойств продолжаются.

Оптические свойства кристаллов $A_{3} B C_{3} D_{2} \mathrm{O}_{14}$ характеризуются отсутствием электронных и колебательных переходов в спектральной области $0.2-8 \mu \mathrm{m}$ (окно прозрачности). Фундаментальными характеристиками оптических кристаллов являются показатели преломления $n$ и их дисперсионная зависимость $n(\lambda)$, лежащие в основе структурной рефрактометрии [2]. Знание показателей преломления $n(\lambda)$ необходимо при расчете эксплуатационных характеристик приборов и устройств с использованием оптических материалов, а также для применения рефрактометрических данных в структурной химии.

Одной из задач структурной рефрактометрии является нахождение корреляций между оптическими (показатели преломления) и кристаллохимическими характеристиками (химическая связь, координация атомов, тип струк- туры) ионных кристаллов [2,3]. Несмотря на то, что семейство лангасита уже насчитывает более двух сотен соединений и твердых растворов, только для менее десятка из них известны экспериментальные значения показателей преломления [4-6]. Для измерений показателей преломления лангаситов требуется получать их в виде объемных монокристаллов высокого оптического качества. Рост таких кристаллов представляет сложную технологическую задачу и требует больших ресурсных затрат. Кроме измеренных в экспериментах показателей преломления, в работе [1] методом молекулярной рефракции проведен теоретический расчет показателей преломления для пятнадцати новых кристаллов. Этим ограничивается объем рефрактометрических данных для кристаллов семейства лангасита. Поскольку кристаллы $A_{3} B C_{3} D_{2} \mathrm{O}_{14}$ имеют сходные особенности строения, представляет интерес поиск для них корреляций между показателями преломления и структурными характеристиками.

Целью настоящей работы является изучение взаимосвязи между параметрами дисперсионных кривых показателей преломления $n(\lambda)$ и координационными числами катионов $N_{c a t}$ для оптических кристаллов семейства лангасита.

\section{2. Структурный тип $\mathrm{Ca}_{3} \mathrm{Ga}_{2} \mathrm{Ge}_{4} \mathrm{O}_{14}$}

Родоначальником структурного типа кристаллов, названных впоследствии семейством лангасита (лантангаллиевого силиката $\mathrm{La}_{3} \mathrm{Ga}_{5} \mathrm{SiO}_{14}$ ) является кальцийгаллиевый германат $\mathrm{Ca}_{3} \mathrm{Ga}_{2} \mathrm{Ge}_{4} \mathrm{O}_{14}$. Впервые соединение $\mathrm{Ca}_{3} \mathrm{Ga}_{2} \mathrm{Ge}_{4} \mathrm{O}_{14}$ было синтезировано в [7], его кристаллическая структура изучена в [8]. Структура $\mathrm{Ca}_{3} \mathrm{Ga}_{2} \mathrm{Ge}_{4} \mathrm{O}_{14}$ подобна структуре пьезоэлектрического кристалла кварца и относится к тригональной сингонии, тригонально- 
трапецоэдрическому классу симметрии 32, пр.гр. P321 с одной формульной единицей в элементарной ячейке $(Z=1)$.

В элементарной ячейке кристаллов семейства лангасита $A_{3} B C_{3} D_{2} \mathrm{O}_{14}$ находится 23 иона. Крупные катионы $A$ находятся в позициях $3 e$ на двойных осях симметрии. Они окружены восемью анионами кислорода, образуя координационный полиэдр (томсоновский куб) $\left[A \mathrm{O}_{8}\right]$. Катионы $B$ находятся в позициях $1 a$ на пересечении двойной и тройной осей симметрии, в октаэдрах $\left[B \mathrm{O}_{6}\right]$. Катионы $C$ находятся в позициях $3 f$ на двойных осях, в тетраэдрах $\left[\mathrm{CO}_{4}\right]$. Катионы $D$ находятся в позициях $2 d$ на тройных осях, в тетраэдрах $\left[D \mathrm{O}_{4}\right]$. Для позиций $3 e, 1 a$ и $(3 f, 2 d)$ характерна восьмерная, шестерная и четверная координация по кислороду и координационное число (КЧ) катионов равно $N_{c a t}=8,6$ и 4 соответственно.

Все позиции $3 e, 1 a, 3 f$ и $2 d$ допускают широкие изоморфные замещения катионов, при этом их координаты, полиэдры и КЧ остаются неизменными.

Четыре вида катионных полиэдров упакованы в два слоя, которые попеременно располагаются вдоль оптической оси (кристаллографической оси $c$ ) [8]. Первый слой состоит из тетраэдров $\left[C \mathrm{O}_{4}\right]$ и $\left[D \mathrm{O}_{4}\right]$, второй слой - из октаэдров $\left[B \mathrm{O}_{6}\right]$ и томсоновских кубов $\left[A \mathrm{O}_{8}\right]$.

Для стабильности структуры $A_{3} B C_{3} D_{2} \mathrm{O}_{14}$ существенным фактором является то обстоятельство, что кристаллический каркас, состоящий из октаэдров $\left[B \mathrm{O}_{6}\right]$ и тетраэдров $\left[\mathrm{CO}_{4}\right]$ и $\left[\mathrm{DO}_{4}\right]$, стабилизируется крупными катионами (например, $\mathrm{La}^{3+}, \mathrm{Pr}^{3+}$ и $\mathrm{Nd}^{3+}$ ) в восьмерной координации. Напротив, крупные катионы в октаэдрических и тетраэдрических позициях дестабилизируют структуру, поэтому позиции $B, C$ и $D$ занимают катионы меньшего радиуса. При этом размер тетраэдра $\left[D O_{4}\right]$ меньше, чем тетраэдра $\left[\mathrm{CO}_{4}\right]$, в результате катионы меньшего размера будут размещаться в позиции $D$, а большего - в позиции $C$.

Несмотря на то, что кристаллы семейства лангасита обладают широким изоморфизмом атомов (разных сортов и ионных радиусов) в катионных позициях, они имеют в дифракционных исследованиях узкие интенсивные брэгговские пики, свидетельствующие об их регулярной и совершенной средней структуре [9].

\section{3. Дисперсионные зависимости $n(\lambda)$ в ионных кристаллах}

Для ионных кристаллов вдали от полосы поглощения применима модель эффективного осциллятора (уравнение Зельмейера)

$$
n^{2}-1=A_{0} \lambda^{2} /\left(\lambda^{2}-\lambda_{0}^{2}\right),
$$

где $A_{0}$ - множитель, связанный с силовыми характеристиками осцилляторов и $\lambda_{0}-$ характеристическая длина волны для края УФ поглощения. Для определения параметров $A_{0}$ и $\lambda_{0}$ уравнение (1) преобразуют к линейному виду

$$
\left[n^{2}-1\right]^{-1}=-A / \lambda^{2}+B
$$

где $A=\lambda_{0}^{2} / A_{0}, B=1 / A_{0}$ и $\lambda_{0}^{2}=A / B$. Формула (1) для эффективного осциллятора может быть приведена к виду (уравнение Вемпла-Дидоминико) [10,11]:

$$
n^{2}-1=E_{d} E_{0} /\left[E_{0}^{2}-(h v)^{2}\right],
$$

где $h v-$ энергия фотона, $E_{0}$ - энергия осциллятора, $E_{d}$ - дисперсионная энергия. Параметры уравнений (1) и (3) связаны между собой выражениями

$$
\begin{gathered}
E_{0}=h v_{0}=h c / \lambda_{0}, \\
E_{d}=A_{0} E_{0} .
\end{gathered}
$$

В $[10,11]$ было показано, что дисперсионная энергия $E_{d}$ зависит от ряда кристаллохимических параметров

$$
E_{d}=\beta N_{c a t} Z_{a} N_{e},
$$

где $N_{\text {cat }}-$ КЧ катиона, $Z_{a}$ - валентность аниона, $N_{e}-$ эффективное число валентных электронов аниона. Коэффициент пропорциональности равен $\beta=0.26 \pm 0.04 \mathrm{eV}$ для ионных кристаллов и $\beta=0.37 \pm 0.05 \mathrm{eV}$ для ковалентных кристаллов.

Тогда из уравнений (4) и (5) получаем связь между параметрами $A_{0}$ и $\lambda_{0}$ дисперсионных кривых $n(\lambda)$

$$
A_{0}=K \cdot \lambda_{0}
$$

где коэффициент пропорциональности $K=\beta N_{c a t} Z_{a} N_{e} / h c$. Одним из сомножителей в коэффициенте пропорциональности между параметрами $A_{0}$ и $\lambda_{0}$ является КЧ катионов $N_{c a t}$. Для оптических кристаллов семейства лангасита $A_{3} B C_{3} D_{2} \mathrm{O}_{14}$ величина КЧ катионов изменяется в 2 раза: $N_{\text {cat }}=4$ (катионы $C$ и $\left.D\right), N_{\text {cat }}=6$ $\left(\right.$ катионы $B$ ) и $N_{c a t}=8($ катионы $A)$.

\section{4. Корреляция между параметрами кривых $n(\lambda)$ и КЧ катионов для кристаллов семейства лангасита}

Для ионных кристаллов семейства лангасита параметры $Z_{a}=2$ (анион $\mathrm{O}^{2-}$ ) и $N_{e}=8$ (валентные электроны $2 s^{2} 2 p^{6}$ для аниона $\mathrm{O}^{2-}$ ), поэтому величина коэффициента $K$ определяется КЧ катионов. Рассчитанные значения коэффициента пропорциональности в уравнении (6) при $\beta=0.26 \mathrm{eV}$ составляют ( $\lambda_{0}$ измеряется в $\mathrm{nm}) K=1.336 \cdot 10^{-2}, 2.004 \cdot 10^{-2}$ и $2.672 \cdot 10^{-2} \mathrm{~nm}^{-1}$ для $N_{\text {cat }}=4,6$ и 8 соответственно.

Тригональные (одноосные) кристаллы со структурой типа лангасита обладают двумя (обыкновенным $n_{o}$ и необыкновенным $n_{e}$ ) показателями преломления. Они являются оптически положительными кристаллами, для них выполняется условие $n_{e}>n_{o}$. В дальнейшем, все расчеты будут проведены для обыкновенного показателя 
Таблица 1. Параметры дисперсионных кривых показателей преломления $n(\lambda)$ для кристаллов $A_{3} B C_{3} D_{2} \mathrm{O}_{14}$ семейства лангасита

\begin{tabular}{|c|c|c|c|}
\hline Кристалл & Множитель $A_{0}$ & Длина волны $\lambda_{0}, \mathrm{~nm}$ & Источник \\
\hline $\begin{array}{l}\mathrm{La}_{3} \mathrm{Ga}_{5} \mathrm{SiO}_{14} \\
\mathrm{La}_{3} \mathrm{Ga}_{5} \mathrm{GeO}_{14} \\
\mathrm{La}_{3} \mathrm{Ga}_{5 .} \mathrm{Nb}_{0.5} \mathrm{O}_{14} \\
\mathrm{La}_{3} \mathrm{Ga}_{5.5} \mathrm{Ta}_{0.5} \mathrm{O}_{14} \\
\\
\mathrm{Ca}_{2} \mathrm{Ga}_{2} \mathrm{Ge}_{4} \mathrm{O}_{14} \\
\mathrm{Sr}_{2} \mathrm{Ga}_{2} \mathrm{Ge}_{4} \mathrm{O}_{14} \\
\mathrm{~Pb}_{3} \mathrm{Ga}_{2} \mathrm{Ge}_{4} \mathrm{O}_{14}\end{array}$ & $\begin{array}{l}2.503 \\
2.563 \\
2.657 \\
2.631 \\
2.643 \\
2.635 \\
2.133 \\
2.129 \\
2.904\end{array}$ & $\begin{array}{l}128.0 \\
135.2 \\
141.6 \\
135.1 \\
135.1 \\
136.0 \\
127.8 \\
127.7 \\
168.0\end{array}$ & $\begin{array}{c}\text { эксперимент } \\
{[4,6,12,13]}\end{array}$ \\
\hline $\begin{array}{l}\mathrm{La}_{3} \mathrm{Ga}_{5} \mathrm{ZrO}_{14} \\
\mathrm{La}_{3} \mathrm{Ga}_{5} \mathrm{TiO}_{14} \\
\mathrm{La}_{3} \mathrm{Ga}_{5} \mathrm{SnO}_{14} \\
\mathrm{La}_{3} \mathrm{Zr}_{0.5} \mathrm{Ga}_{5} \mathrm{Si}_{0.5} \mathrm{O}_{14} \\
\mathrm{La}_{3} \mathrm{Ta}_{0.25} \mathrm{Ga}_{5.25} \mathrm{Si}_{0.5} \mathrm{O}_{14} \\
\mathrm{La}_{3} \mathrm{Ta}_{0.25} \mathrm{Zr}_{0.5} \mathrm{Ga}_{5.25} \mathrm{O}_{14} \\
\mathrm{La}_{3} \mathrm{SnGa}_{3.1} \mathrm{Al}_{1.9} \mathrm{O}_{14} \\
\mathrm{La}_{2.88} \mathrm{Sr}_{0.12} \mathrm{Ta}_{0.56} \mathrm{Ga}_{5.44} \mathrm{O}_{14} \\
\mathrm{Nd}_{3} \mathrm{Ga}_{5} \mathrm{SiO}_{14} \\
\mathrm{Ba}_{3} \mathrm{Ga}_{2} \mathrm{Ge}_{4} \mathrm{O}_{14} \\
\mathrm{Ba}_{3} \mathrm{TaGa}_{3} \mathrm{Si}_{2} \mathrm{O}_{14} \\
\mathrm{Sr}_{3} \mathrm{TaGa}_{3} \mathrm{Si}_{2} \mathrm{O}_{14} \\
\mathrm{Sr}_{3} \mathrm{NbGa}_{3} \mathrm{Si}_{2} \mathrm{O}_{14} \\
\mathrm{Ca}_{3} \mathrm{TaGa}_{3} \mathrm{Si}_{2} \mathrm{O}_{14} \\
\mathrm{Ca}_{3} \mathrm{NbGa}_{3} \mathrm{Si}_{2} \mathrm{O}_{14}\end{array}$ & $\begin{array}{l}2.535 \\
2.682 \\
2.538 \\
2.529 \\
2.585 \\
2.606 \\
2.558 \\
2.647 \\
2.513 \\
2.232 \\
2.306 \\
2.138 \\
2.106 \\
2.116 \\
2.137\end{array}$ & $\begin{array}{l}132.9 \\
145.3 \\
134.1 \\
129.3 \\
131.8 \\
134.1 \\
133.6 \\
135.1 \\
130.4 \\
120.5 \\
119.8 \\
124.5 \\
134.8 \\
124.5 \\
132.6\end{array}$ & расчет [1] \\
\hline
\end{tabular}

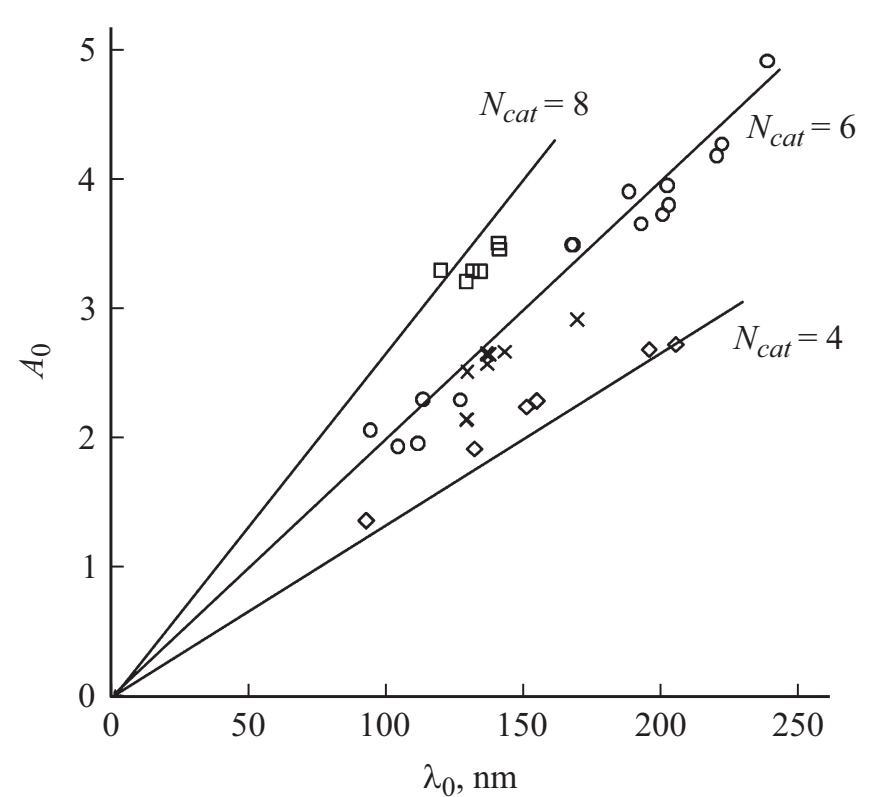

Рис. 1. Корреляция между параметрами экспериментальных кривых $n(\lambda)$ для кристаллов семейства лангасита: наклонные кресты - эксперимент $[4,6,12,13]$, прямые линии — расчет по (6) при $N_{c a t}=4,6$ и 8. Ромбы, кружки и квадраты - экспериментальные данные для оксидных кристаллов с $N_{c a t}=4,6$ и 8 (табл. 2).

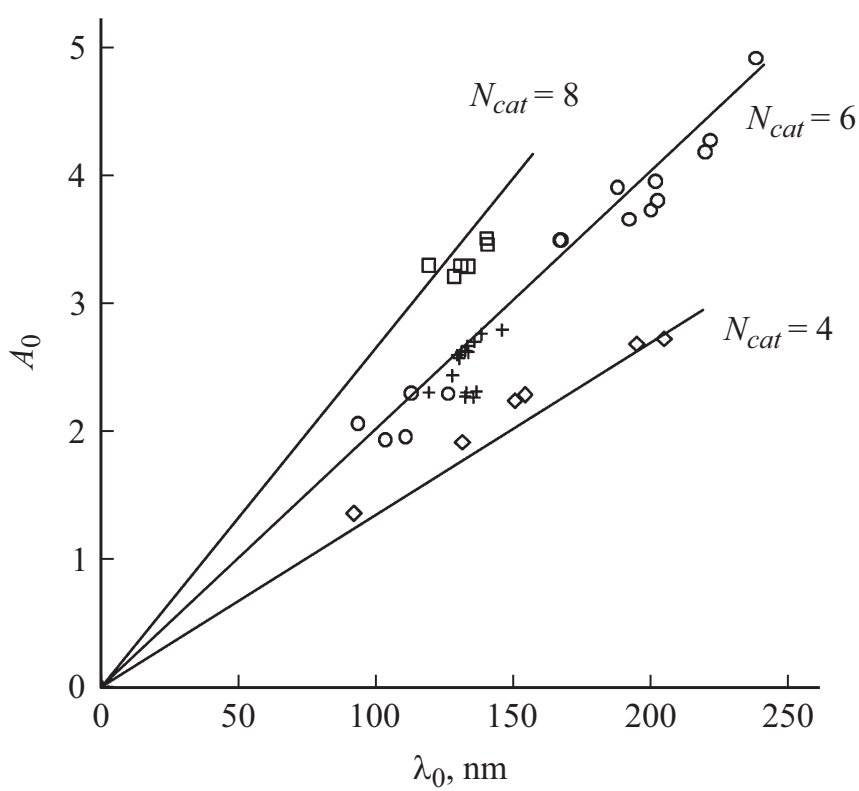

Рис. 2. Корреляция между параметрами рассчитанных кривых $n(\lambda)$ для кристаллов семейства лангасита: прямые кресты - расчет методом молекулярной рефракции [1], прямые линии - расчет по (6) при $N_{c a t}=4,6$ и 8. Ромбы, кружки и квадраты - экспериментальные данные для оксидных кристаллов с $N_{c a t}=4,6$ и 8 (табл. 2). 
Таблица 2. Параметры дисперсионных кривых экспериментальных показателей преломления $n(\lambda)$ для оксидных кристаллов

\begin{tabular}{|c|c|c|c|}
\hline Кристалл & Множитель $A_{0}$ & Длина волны $\lambda_{0}, \mathrm{~nm}$ & Источник \\
\hline \multicolumn{4}{|c|}{ Оксидные кристаллы с $N_{c a t}=4$} \\
\hline $\begin{array}{l}\mathrm{ZnO}_{2} \\
\mathrm{SiO}_{2} \\
\mathrm{LiGaO}_{2} \\
\mathrm{Ga}_{2}\left(\mathrm{MoO}_{4}\right)_{3} \\
\mathrm{~Tb}_{2}\left(\mathrm{MoO}_{4}\right)_{3}\end{array}$ & $\begin{array}{l}2.672 \\
2.711 \\
1.346 \\
1.905 \\
2.229 \\
2.272\end{array}$ & $\begin{array}{r}194.1 \\
204.0 \\
91.4 \\
130.8 \\
149.7 \\
153.4\end{array}$ & {$[5,11]$} \\
\hline \multicolumn{4}{|c|}{ Оксидные кристаллы с $N_{c a t}=6$} \\
\hline $\begin{array}{l}\mathrm{MgO} \\
\mathrm{CaO} \\
\mathrm{Al}_{2} \mathrm{O}_{3} \\
\mathrm{TeO}_{2} \\
\mathrm{TiO}_{2} \\
\mathrm{Y}_{3} \mathrm{Al}_{5} \mathrm{O}_{12} \\
\mathrm{SrTiO}_{3} \\
\mathrm{BaTiO}_{3} \\
\mathrm{LiTaO}_{3} \\
\mathrm{LiNbO}_{3} \\
\mathrm{KTaO}_{3} \\
\mathrm{KTa}_{0.65} \mathrm{Nb}_{0.35} \mathrm{O}_{3} \\
\mathrm{MgAl}_{2} \mathrm{O}_{4} \\
\mathrm{ZnWO}_{4} \\
\mathrm{Ba}_{2} \mathrm{NaNb}_{5} \mathrm{O}_{15}\end{array}$ & $\begin{array}{l}1.947 \\
2.283 \\
2.052 \\
3.718 \\
4.905 \\
2.288 \\
4.173 \\
4.263 \\
3.485 \\
3.895 \\
3.646 \\
3.793 \\
1.926 \\
3.485 \\
3.942\end{array}$ & $\begin{array}{r}109.9 \\
125.5 \\
92.7 \\
199.2 \\
237.1 \\
111.9 \\
218.7 \\
220.7 \\
165.9 \\
186.8 \\
191.1 \\
201.4 \\
102.7 \\
166.5 \\
200.7\end{array}$ & {$[11]$} \\
\hline \multicolumn{4}{|c|}{ Оксидные кристаллы с $N_{c a t}=8$} \\
\hline $\begin{array}{l}\mathrm{ThO}_{2} \\
\mathrm{Zr}_{0.869} \mathrm{Y}_{0.131} \mathrm{O}_{1.934} \\
\mathrm{Zr}_{0.894} \mathrm{Hf}_{0.11} \mathrm{Y}_{0.095} \mathrm{O}_{1.95} \\
\mathrm{Hf}_{0.904} \mathrm{Y}_{0.096} \mathrm{O}_{1.952} \\
\mathrm{Hf}_{0.85} \mathrm{Y}_{0.15} \mathrm{O}_{1.925}\end{array}$ & $\begin{array}{l}3.276 \\
3.285 \\
3.447 \\
3.495 \\
3.282 \\
3.197\end{array}$ & $\begin{array}{l}132.6 \\
118.4 \\
139.7 \\
139.4 \\
130.0 \\
127.6\end{array}$ & {$[5]$} \\
\hline
\end{tabular}

преломления, поскольку показатели преломления $n_{e}$ и $n_{o}$ различаются незначительно $(\Delta n=0.01-0.03[4])$.

В $[4,6,12,13]$ имеются экспериментальные данные по дисперсии показателей преломления для семи кристаллов семейства лангасита, в [1] для пятнадцати кристаллов они рассчитаны методом молекулярной рефракции. Все кристаллы обладают слабой дисперсионной зависимостью показателей преломления $n(\lambda)$. Их значения параметров $A_{0}$ и $\lambda_{0}$ для обыкновенного показателя $n_{o}$ приведены в табл. 1 .

На рис. 1 показаны зависимость экспериментальных параметров $A_{0}$ от $\lambda_{0}$ для кристаллов со структурой лангасита и теоретические зависимости $A_{0}=K \lambda_{0}$ при КЧ катионов $N_{c a t}=4$ (позиции $3 f$ и $2 d$ ), $\quad N_{c a t}=6$ (позиции 1a) и $N_{c a t}=8$ (позиции $3 e$ ). На рис. 2 показаны аналогичные зависимости для рассчитанных методом молекулярной рефракции параметров $A_{0}$ от $\lambda_{0}$ кристаллов со структурой лангасита. Для сравнения на рис. 1 и 2 также приведены экспериментальные данные для трех групп оксидных кристаллов с известными КЧ катионов $N_{c a t}=4,6$ и $8[5,11]$, для которых значения $A_{0}$ и $\lambda_{0}$ нами были рассчитаны по приведенным в $[5,11]$ значениям энергий $E_{0}$ и $E_{d}$ (табл. 2). Можно видеть, что как экспериментальные (рис. 1), так и рассчитанные рефрактометрические данные (рис. 2) кристаллов семейства лангасита сильно отклоняются от теоретических зависимостей $A_{0}=f\left(\lambda_{0}\right)$ при $N_{c a t}=4$ и 8 , и близки к теоретической зависимости при $N_{c a t}=6$.

На рис. 3 приведены общая зависимость экспериментальных и рассчитанных параметров $A_{0}$ от $\lambda_{0}$ для кристаллов со структурой лангасита и теоретическая зависимости $A_{0}=K \lambda_{0}$ при КЧ катионов $N_{\text {cat }}=6$ в границах изменения параметра $\beta=0.26 \pm 0.04 \mathrm{eV}$. Видно, что для некоторых лангаситовых кристаллов наблюдается отклонение вниз параметров $A_{0}, \lambda_{0}$ от теоретической зависимости $N_{c a t}=6$.

Это может быть связано со следующими причинами. Во-первых, наиболее вероятно, что корреляционная 


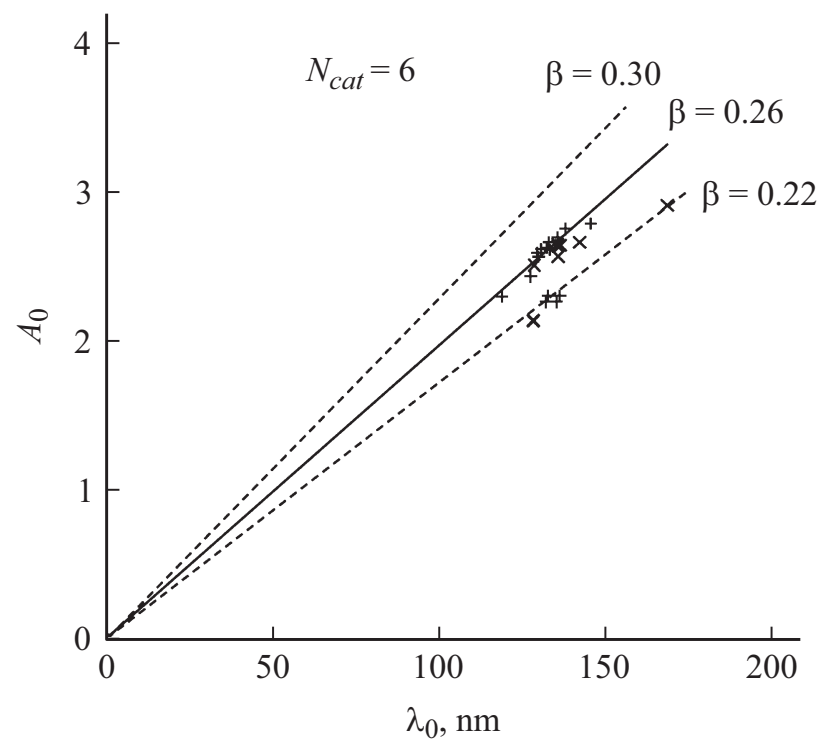

Рис. 3. Корреляция между параметрами экспериментальных (наклонные кресты) и расчетных (прямые кресты) кривых $n(\lambda)$ для кристаллов семейства лангасита: прямая линия - расчет по (6) при $N_{c a t}=6$ и $\beta=0.26 \mathrm{eV}$, штриховые линии границы расчета при $\beta=0.26 \pm 0.04 \mathrm{eV}$.

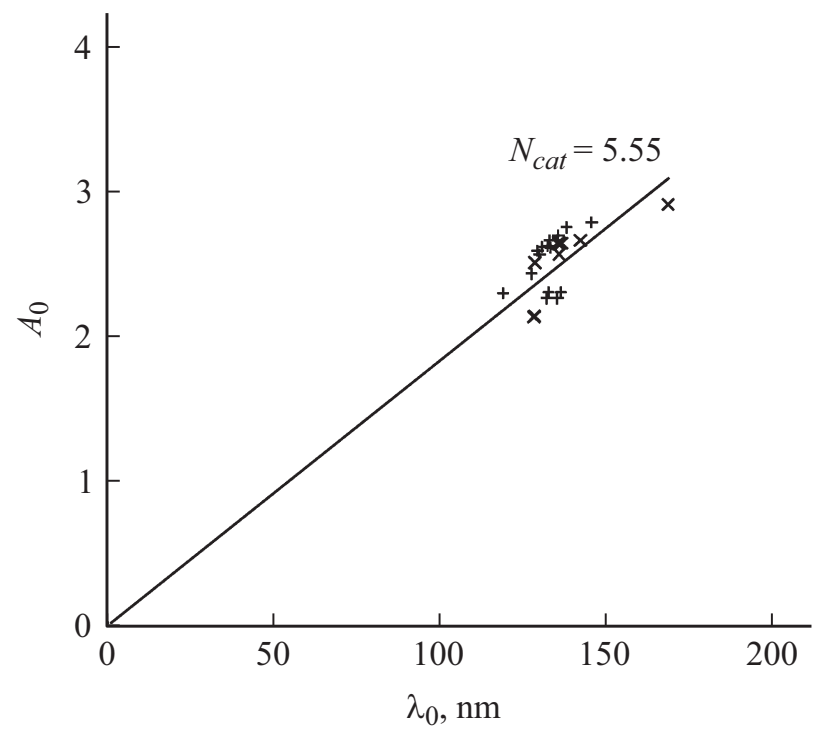

Рис. 4. Корреляция между параметрами экспериментальных (наклонные кресты) и расчетных (прямые кресты) дисперсионных кривых $n(\lambda)$ для кристаллов семейства лангасита: прямая линия - расчет по (6) при $N_{c a t}=5.55$ и $\beta=0.26 \mathrm{eV}$.

зависимость соответствует среднему значению для КЧ катионов с учетом их весовых множителей в структуре лангасита $A_{3} B C_{3} D_{2} \mathrm{O}_{14}$ (рис. 4)

$$
N_{\text {cat }}=\left(3 N_{A}+N_{B}+3 N_{C}+2 N_{D}\right) / 9=5.55 .
$$

Во-вторых, возможно необходимо учитывать ковалентный вклад в химическую связь в лангаситах, для которых наблюдается отклонение от теоретической зависимости $N_{\text {cat }}=6$.

\section{5. Заключение}

Оксиды семейства лангасита $A_{3} B C_{3} D_{2} \mathrm{O}_{14}$ отличаются высокой степенью ионности химической связи и высокой „чувствительностью“ их оптических свойств к КЧ катионов. Показано, что для оптических кристаллов семейства лангасита взаимосвязь коэффициентов $A_{0}$ и $\lambda_{0}$ из дисперсионных зависимостей $n(\lambda)$ определяется средним значением КЧ катионов $N_{c a t}=5.55$. Полученная корреляция подтверждает применимость метода молекулярной рефракции (ионных рефракций оксидов) для расчета показателей преломления лангаситовых кристаллов.

\section{Благодарности}

Автор выражает благодарность А.Ф. Константиновой и Т.Г. Головиной за просмотр статьи и сделанные замечания.

\section{Финансирование работы}

Работа выполнена при поддержке Министерства науки и высшего образования в рамках выполнения работ по Государственному заданию ФНИЦ „Кристаллография и фотоника“ РАН.

\section{Список литературы}

[1] А.Ф. Константинова, Т.Г. Головина, Б.В. Набатов, А.П. Дудка, Б.В. Милль. Кристаллография 60, 1950 (2015).

[2] С.С. Бацанов. Структурная рефрактометрия. Высш. шк., M. (1976). 304 c.

[3] Н.И. Сорокин. Неорган. материалы 55, 80 (2019).

[4] О.А. Батурина, Б.Н. Гречушников, А.А. Каминский, А.Ф. Константинова, А.А. Маркосян, Б.В. Милль, Г.Г. Ходжабадян. Кристаллография 32, 406 (1987).

[5] R.D. Shannon, R.C. Shannon, O. Medenlach, R.X. Fischer. J. Phys. Chem. Ref. Data. 31, 931 (2002).

[6] А.В. Буташин, Л.Е. Ли, А.Ф. Константинова, И.А. Гудим. Кристаллография 49, 524 (2004).

[7] Б.В. Милль, А.В. Буташин, А.М. Эллерн, А.А. Майер. Изв. АН СССР. Неорган. материалы 17, 1648 (1981).

[8] Е.Л. Белоконева, Н.В. Белов. ДАН СССР 260, 1363 (1981).

[9] А.П. Дудка. Кристаллография 62, 374 (2017).

[10] S.H. Wemple, M. Di Domenico. Phys. Rev. Lett. 23, 1156 (1969.)

[11] S.H. Wemple, M. Di Domenico. Phys. Rev. B. 3, 1338 (1971).

[12] О.А. Бузанов, Е.В. Забелина, Н.С. Козлова. Кристаллография 52, 690 (2007).

[13] J. Stade, L. Bohate, M. Hengst. Cryst. Res. Technol. 10, 1113 (2002).

Редактор Ю.Э. Китаев 